\title{
Pengaruh Budaya Organisasi dan Promosi Jabatan terhadap Kinerja Karyawan PT. Taspen Kantor Cabang Utama Medan
}

\section{The Determine of Organizational Culture and Job Promotion on Employee Performance at PT.Taspen Kantor Cabang Utama Medan}

\author{
Reza Nurul Ichsan 1)* \& Lukman Nasution') \\ 1) Program Studi Manajemen, Fakultas Ekonomi, Universitas Pembinaan Masyarakat \\ Indonesia, Indonesia \\ 2) Program Studi Manajemen, Fakultas Ekonomi, Universitas Muslim Nusantara Al washliyah \\ Medan, Indonesia \\ Diterima: 16 September 2020 ; Direview:26 September 2020 ; Disetujui : 14 Oktober 2020
}

*Coresponding Email: rezaichsan31@gmail.com

\begin{abstract}
Abstrak
Tujuan penelitian ini adalah untuk mengetahui pengaruh budaya organisasi dan promosi jabatan terhadap kinerja karyawan Pada PT. Taspen (Persero) Kantor Cabang Utama Medan. objek penelitian dibatasi hanya terhadap variabel budaya organisasi dan promosi jabatan sebagai variabel bebas dan kinerja karyawan sebagai variabel terikat. Sampel yang diambil dalam penelitian ini adalah sebanyak 72 Responden. Metode Analisis yang dipakai yaitu analisis regresi linier berganda yang mana konstanta sebesar 0,876 yang artinya menunjukkan bahwa jika variabel budaya organisasi dan promosi jabatan dianggap konstan maka tingkat variabel kinerja karyawan nilainya positif yaitu sebesar 0.876 . Sedangkan hasil koefisien korelasi X1 sebesar 0.248 yang artinya jika budaya organisasi mengalami peningkatan maka kinerja karyawan akan mengalami peningkatan sebesar 0.248 dan koefisien X2 sebesar 0.851 yang artinya jika variabel promosi jabatan mengalami peningkatan maka kinerja karyawan akan mengalami peningkatan sebesar sebesar 0.851 , ketiga variabel ini saling memiliki hubungan keterikatan yang positif terhadap kinerja karyawan serta memiliki nilai signifikannya adalah $0,000<$ dari 0,005.
\end{abstract}

Kata Kunci : Budaya Organisasi; Promosi Jabatan; Kinerja Karyawan.

\begin{abstract}
The purpose of this study was to determine whether there is influence of organizational culture and job promotion on employee performance at PT. Taspen (Persero) Kantor Cabang Utama Medan. The object of research is limited to organizational culture variable and job promotion as independent variable and employee performance as dependent variable. Samples, ie as many as 72 Respondents. Analysis method used is multiple linear regression analysis which kosntanta equal to 0,876 which means indicate that if variable of organizational culture and job promotion is considered constant then level of employee performance variable positive value that is equal to 0876. While the results of correlation coefficient X1 of 0.248 which means if the organizational culture has increased the employee performance will experience an increase of 0.248 and X2 coefficient of 0.851 which means that if job promotion variables increased the employee performance will experience an increase of 0.851, these three variables each have The relationship of positive attachment to employee performance and has a significant value is $0.000<$ from 0.005 .
\end{abstract}

Key words : Organizational Culture; Job Promotion; Employee Performance

How to Cite: Ichsan, R.N \& Nasution, L. (2020). Pengaruh Budaya Organisasi dan Promosi Jabatan Terhadap Kinerja Karyawan PT. Taspen (PERSERO) Kantor Cabang Utama Medan. Journal of Education, Humaniora and Social Sciences (JEHSS). 3(2): 459-466. 


\section{PENDAHULUAN}

Manajemen sumber daya manusia merupakan elemen kunci dalam perencanaan strategis setiap bisnis. Manajemen sumber daya yang strategis berkenaan dengan perencanaan, pengawasan, evaluasi, dan pengembangan sumber daya manusia yang ada dalam perusahaan agar memperoleh sebanyak mungkin nilai tambah.Pengelolaan sumber daya manusia yang dimaksudkan adalah bahwa perusahaan harus mampu untuk menyatukan persepsi, atau cara pandang seorang karyawan, dan pimpinan perusahaan dalam rangka untuk mencapai tujuan perusahaan, antara lain melalui pembentukan mental bekerja yang baik dengan dedikasi, dan loyalitas yang tinggi terhadap pekerjaannya.

Kinerja karyawan merupakan hal yang merupakan hal yang bersifat individual, karena setiap karyawan mempunyai tingkat kemampuan yang berbeda-beda dalam mengerjakan tugasnya. Kinerja tergantung pada kombinasi antara kemampuan, usaha, dan kesempatan yang diperoleh. Hal ini dapat dilihat dari kinerja kerja karyawan dalam bekerja, untuk periode waktu tertentu dan penekanannya pada hasil kerja yang diselesaikan karyawan dalam periode waktu tertentu. Faktor yang mempengaruhi kinerja karyawan salah satunya yaitu melalui penciptaan budaya organisasi yang baik, dan dapat diterima oleh seluruh karyawan, dan memotivasi semangat kerja karyawan dalam bentuk promosi jabatan agar kinerjanya dapat meningkat (Nasution eta al.,2020; Nasution et al., 2020; Purba et al., 2020; Fikri \& Nasution, 2018).

Budaya yang baik diciptakan oleh perusahaan untuk menjadi motivasi bagi karyawan, agar karyawan menghasilkan kinerja yang maksimal. Budaya organisasi penting di perhatikan oleh organisasi, karena menyangkut kebiasaan-kebiasaan yang terjadi dalam hirarki organisasi yang mewakili norma-norma perilaku yang diikuti oleh seluruh anggota organisasi (Latief, et al., 2018; Syardiansah, et al., 2020; Haryati, et al., 2019). Budaya organisasi merupakan salah satu faktor yang dapat meningkatkan kinerja karyawan, dan bagi setiap insan yang terlibat didalam perusahaan karena budaya merupakan jati diri dari setiap insan yang terlibat meski mereka mempunyai tujuan yang berbeda-beda. Dengan adanya budaya yang kuat didalam perusahaan, maka semua yang terlibat akan memiliki tujuan yang sama, sehingga karyawan akan menjalankan tugasnya dengan baik (Ichsan, 2019; Gaol et al., 2020; Nasution et al., 2018; Nasution et al., 2018; Nasution et al., 2018; Nasution et al., 2018; Nasution et al., 2017; Nasutionet al., 2020).

Salah satu bentuk penghargaan perusahaan terhadap para karyawannya adalah dalam bentuk promosi jabatan. Hal ini dilakukan guna memaksimalkan kualitas sumber daya manusia yang dimiliki, dan berusaha untuk melakukan inovasi-inovasi bagi para karyawannya sehingga dapat bekerja dengan efektif dan efisien serta tidak menimbulkan kejenuhan dalam pekerjaan (Ichsan et al., 2020; Ichsan et al 2019; Nasution et al., 2020; Yusuf et al., 2019; Ichsan, 2019; Gaol et al., 2020).

Promosi yang dilakukan di dalam perusahaan juga mempunyai tujuan, memberikan kesempatan kepada karyawan untuk mengembangkan kreativitas dan inovasinya, yang lebih baik demi keuntungan optimal perusahaan, selain itu promosi juga bertujuan untuk menambah dan memperluas pengetahuan serta pengalaman kerja para karyawan, dan ini merupakan daya dorong bagi karyawan lain untuk meningkatkan kinerjanya (Mora, Z., et al., 2020; Latief, et al., 2019; Latief, et al., 2019).

\section{METODE PENELITIAN}

Lokasi yang menjadi tempat penelitian adalah pada PT. Taspen (Persero) Kantor Cabang Utama Medan yang beralamat di Jln. H. Adam Malik No.64 Medan, Waktu penelitian dimulai pada bulan Mei sampai September 2017. Sampel yang diambil dalam penelitian ini adalah sebanyak 96\% dari jumlah total keseluruhan 72 Karyawan, yaitu sebanyak 72 Responden.

Sumber data yang dilakukan dalam penelitian ini adalah Data Kuantitatif. Data kuantitatif yaitu data yang diperoleh dalam bentuk angka - angka yang dapat dihitung, yang diperoleh dari wawancara dan kuesioner dari karyawan yang ada di PT. Taspen (Persero) Kantor Cabang Utama Medan yang beralamat di Jln. H. Adam Malik No.64 Medan. Teknik analisis data dalam penelitian 
ini dengan menggunakan: Uji t (Parsial), Uji F (Serempak), dan Uji Koefisien Determinasi (RSquare/R2). Penghitungan uji analisis dalam penelitian ini dilakukan dengan menggunakan bantuan program Statistical Package for Social Science (SPSS).

\section{HASIL DAN PEMBAHASAN \\ Uji Validitas}

Uji validitas dilakukan untuk mengukur apakah data yang telah didapat setelah penelitian merupakan data yang valid dengan alat ukur yang digunakan (kuesioner). Bila koefisien korelasi (r) lebih besar dari $r$ table (0.3), maka pertanyaan tersebut dikatakan valid.Pengujian validitas dilakukan dengan menggunakan program SPPS 23.0 dengan hasil sebagai berikut:

Setelah di uji validitas variabel X1 (Budaya Organisasi) Item pertanyaan sebanyak 15 semua dinyatakan valid karena nilai corrected item-total corellation $>0,3$. Maka butir pertanyaan tersebut dinyatakan valid dan layak digunakan dalam penelitian ini.

Setelah di uji validitas variabel X2 (Promosi Jabatan) item pertanyaan sebanyak 12 semua dinyatakan valid karena nilai corrected item-total correlation $>0,3$. Maka butir pertanyaan tersebut dinyatakan valid dan layak digunakan dalam penelitian ini.

Sedangkan uji validitas variabel Y (Kinerja Karyawan) item pertanyaan sebanyak 14 dan semua dinyatakan valid karena nilai corrected item-total correlation $>0,3$. Maka butir pertanyaan tersebut dinyatakan valid dan layak digunakan dalam penelitian ini.

\section{Uji Reliabilitas}

Uji reliabilitas digunakan untuk melihat apakah alat ukur yang digunakan (kuesioner) menunjukkan konsistensi didalam mengukur gejala yang sama. Adapun hasil uji reliabilitasnya dengan sebagai berikut: 1) Berdasarkan hasil output reliabilitas variabel X1 dapat diketahui bahwa variabel X1 adalah reliable dengan Cronbach's Alpha adalah 0,947 atau lebih besar dari 0,70. Berdasarkan hasil ini juga dapat disimpulkan bahwa item pertanyaan kuesioner sudah memiliki reliabilitas yang tinggi; 2) Berdasarkan hasil output reliabilitas variabel X2 dapat diketahui bahwa variabel X2 adalah reliable dengan Cronbach's Alpha adalah 0,832 atau lebih besar dari 0,70. Berdasarkan hasil ini juga dapat disimpulkan bahwa item pertanyaan kuesioner sudah memiliki reliabilitas yang tinggi; 3) Berdasarkan hasil output reliabilitas variabel Y dapat diketahui bahwa variabel Y adalah reliable dengan Cronbach's Alpha adalah 0,915 atau lebih besar dari 0,70. Berdasarkan hasil ini juga dapat disimpulkan bahwa item pertanyaan kuesioner sudah memiliki reliabilitas yang tinggi.

\section{Analisis Statistik Regresi Linear Berganda}

Metode analisis regresi berganda digunakan untuk mengetahui berapa besar pengaruh variabel bebas terhadap variabel terikat. Adapun bentuk umum persamaan regresi yang digunakan adalah sebagai berikut:

$$
\begin{aligned}
& \mathrm{Y}=\alpha+\mathrm{b}_{1} \mathrm{X}_{1}+\mathrm{b}_{2} \mathrm{X}_{2}+\mathbf{\Sigma} \\
& \text { Dimana }: \\
& \mathrm{Y}=\text { Kinerja karyawan } \\
& \mathrm{X} 1=\text { Budaya Organisasi } \\
& \mathrm{X} 2=\text { Promosi Jabatan } \\
& \alpha=\text { Konstanta }
\end{aligned}
$$

b1, b2 = Koefisien regresi

$\sum$ = Variabel lain yang tidak diikutkan dalam penelitian

Berdasarkan hasil pengujian melalui SPSS versi 23 for windows, maka hasil persamaan regresi linear berganda dapat dilihat pada Tabel 1 berikut ini: 
Reza Nurul Ichsan \& Lukman Nasution, Pengaruh Budaya Organisasi dan Promosi Jabatan Terhadap

Tabel 1. Hasil Regresi Linier Berganda

Coefficients $^{\mathrm{a}}$

\begin{tabular}{|c|c|c|c|c|c|}
\hline \multirow{2}{*}{ Model } & \multicolumn{2}{|c|}{ Unstand ardized Coefficients } & \multirow{2}{*}{$\begin{array}{l}\text { Standardized Coefficients } \\
\text { Beta }\end{array}$} & & \multirow{2}{*}{ Sig. } \\
\hline & $\bar{B}$ & Std. Error & & & \\
\hline 1(Constant) & .876 & 5.790 & & .151 & .880 \\
\hline Budaya & .248 & .073 & .315 & 3.416 & .001 \\
\hline $\begin{array}{l}\text { Organisasi Promosi } \\
\text { Jabatan }\end{array}$ & i .851 & .146 & .536 & 5.818 & .000 \\
\hline
\end{tabular}

a. Dependent Variable: Kinerja Karyawan

Sumber: Hasil pengolahan SPSS 23, 2020

Berdasarkan Tabel 1, diketahui pada kolom kedua (unstandardized Coefficients) bagian B diperoleh nilai b1 variabel Budaya Organisasi sebesar 0.248 nilai b2 dan variabel Promosi Jabatan sebesar 0.851 dan nilai konstanta (a) adalah 0.876 , maka diperoleh persamaan regresi linier berganda sebagai berikut:

$\mathrm{Y}=0.876+0.248 \mathrm{X}_{1}+0.851 \mathrm{X}_{2}+\sum$

Berdasarkan persamaan diatas maka dapat diuraikan sebagai berikut :

b. Konstanta $(a)=0.876$, ini menunjukkan bahwa jika variabel Budaya Organisasi dan promosi Jabatan dianggap konstan maka tingkat variabel Kinerja Karyawan (Y) sebesar 0.876.

c. Koefisien b1 $\left(\mathrm{X}_{1}\right)=0.248$, menunjukkan bahwa variabel Budaya Organisasi berpengaruh positif terhadap kinerja karyawan atau dengan kata lain jika variabel Budaya Organisasi ditingkatkan maka Kinerja Karyawan akan bertambah sebesar 0.248.

d. Koefisien b2 $\left(\mathrm{X}_{2}\right)=0.851$, menunjukkan bahwa variabel Promosi Jabatan berpengaruh secara positif terhadap Kinerja Karyawan. Dengan kata lain jika variabel Promosi Jabatan ditingkatkan maka Kinerja Karyawan akan bertambah sebesar 0.851 .

Bilamana kondisi saat ini sama dengan masa yang akan datang atau waktu yang berbeda, maka generalisasi diatas dapat digunakan atau berlaku. Dengan demikian bila keadaan Cateris Paribus dimana faktor lain yang tidak diikutkan dianggap tetap. Sehingga faktor tersebut dapat diabaikan, maka hasil temuan diatas dapat ditulis sebagai berikut : $\mathrm{Y}=0.876+0.248 \mathrm{X} 1+0.851$ $\mathrm{X} 2$.

\section{Uji Normalitas}

Uji Normalitas Salah satu cara untuk melihat normalitas adalah dengan melihat grafik histrogram dan grafik normal plot yang membandingkan antara dua absorvasi dengan distribusi yang mendekati distribusi normal.

a. Pendekatan Histogram

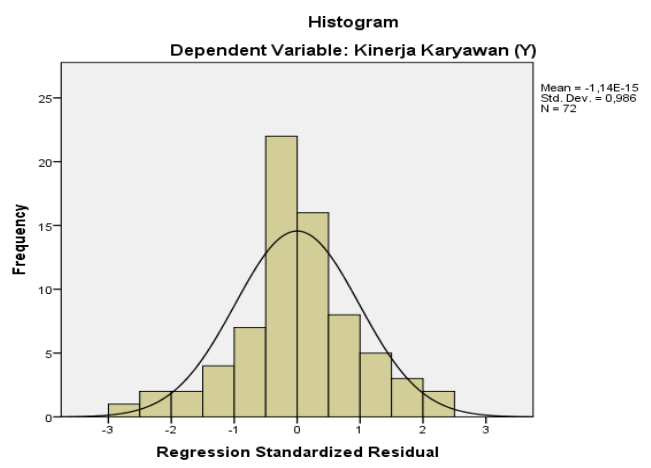

Gambar 1. Histogram 


\section{Sumber : Hasil Pengolahan SPSS 23}

Berdasarkan diatas dapat diketahui bahwa variabel berdistribusi normal, hal ini ditunjukkan oleh distribusi data yang berbentuk lonceng dan tidak melenceng ke kiri atau ke kanan.

b. Pendekatan Grafik

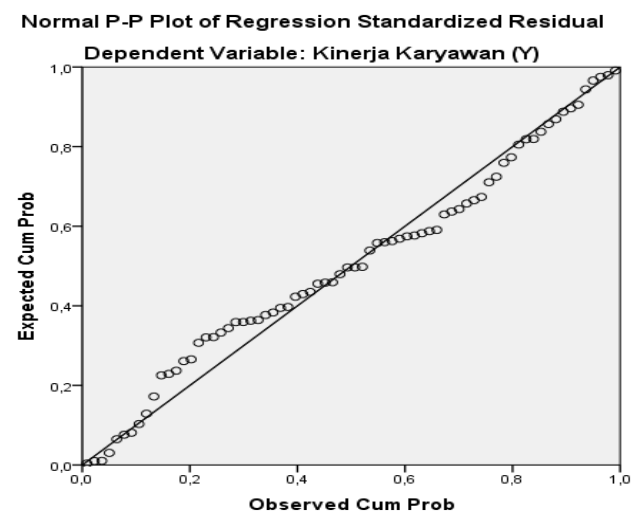

Gambar 2. Uji Plot Normalitas

Sumber: Hasil Pengelohan SPSS 23

Pada Gambar 2 menunjukkan bahwa pada scatter plot terlihat titik yang mengikuti data di sepanjang garis diagonal. Hal ini menunjukkan bahwa residual peneliti normal.

\section{Uji Heteroskedastisitas}

Uji heteroskedastisitas adalah Uji yang menilai apakah terjadi ketidaksamaan varian dari residual untuk semua pengamatan pada model regresi linier. Ada beberapa cara untuk mendekati ada atau tidaknya heteroskedastisitas yaitu:

\section{a. Metode Grafik}

Dasar analisis adalah jika tidak ada pola yang jelas, serta titik-titik menyebar diatas dan di bawah angka 0 pada sumbu Y, maka tidak terjadi Heteroskedastisitas, sedangkan jika ada pola tertentu seperti titik-titik yang ada membentuk pola tertentu yang teratur maka mengindikasikan telah terjadi heterokedastisitas.

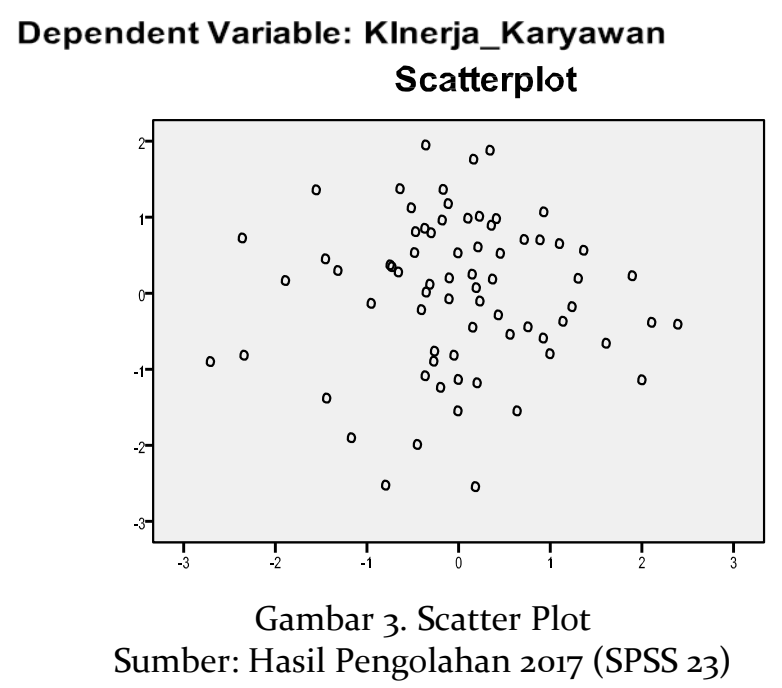

Berdasarkan gambar 3 dapat terlihat bahwa tidak ada pola yang jelas serta titik-titik menyebar diatas dan di bawah angka 0 pada sumbu Y, maka berdasarkan metode grafik tidak 
terjadi heteroskedastisitas pada model regresi layak dipakai untuk memprediksi kinerja karyawan berdasarkan masukan variabel Budaya Organisasi dan Promosi Jabatan.

\section{b. Pengujian Koefisien Determinasi $\left(\mathrm{R}^{2}\right)$}

Pengujian Koefisien determinan $\left(\mathrm{R}^{2}\right)$ digunakan untuk mengukur seberapa besar kontribusi variabel bebas terhadap variabel terikat, atau dengan kata lain angkat tersebut dapat mengukur seberapa dekatkah garis regresi yang terestimasi dengan data sesunguhnya. Koefisien determinasi berkisar antara nol sampai satu $\left(0 \leq \mathrm{R}^{2} \geq 1\right)$.

Jika $\mathrm{R}^{2}$ semakin besar atau mendekati satu, maka dapat dikatakan bahwa pengaruh variabel bebas $\left(\mathrm{X}_{1}\right)$ dan $\left(\mathrm{X}_{2}\right)$ adalah besar terhadap variabel terikat $(\mathrm{Y})$. Hasil pengujian koefisien determinasi dapat dilihat pada tabel 2 berikut ini:

Tabel 2. Hasil Pengujian Koefisien Determinasi Model Summary

\begin{tabular}{lllll}
\hline Model & $\mathrm{R}$ & R Square & Adjusted R Square & Std. Error of the Estimate \\
\hline 1 & $.741^{\mathrm{a}}$ & .550 & .537 & 6.62831 \\
\hline
\end{tabular}

a. Predictors: (Constant), Promosi Jabatan, Budaya Organisasi

b. Dependent Variable: Kinerja Karyawan

Sumber : Hasil Pengelolaan SPSS 23, 2020

Berdasarkan hasil dari Tabel 2 dapat diketahui bahwa:

a. Nilai $\mathrm{R}$ sebesar 0.741 sama dengan $74.1 \%$ berarti hubungan antara variabel Budaya Organisasi (X1) dan Promosi Jabatan ( $\mathrm{X}_{2}$ ) terhadap variabel Kinerja Karyawan (Y) sebesar $74.1 \%$ artinya hubungannya erat.

b. Nilai Adjusted R Square 0.537 berarti 53,7\% kinerja karyawan dapat di jelaskan oleh variabel Budaya Organisasi dan Variabel Promosi Jabatan. Sedangkan sisanya 46,3\% dapat dijelaskan oleh faktor-faktor lain yang tidak dimasukkan sebagai variabel dalam penelitian ini.

c. Standard Error of the Estimate artinya untuk mengukur variasi dari nilai yang diprediksi. Nilai Standard Error of the Estimate 6.62831.

\section{Pengujian Hipotesis \\ Uji Signifikansi Simultan (Uji F)}

Pengujian ini dilakukan untuk melihat secara bersama-sama pengaruh atau hubungan positif dan signifikan variabel bebas $\left(\mathrm{X}_{1}, \mathrm{X}_{2}\right)$ berupa Budaya Organisasi dan Promosi Jabatan terhadap variabel terikat $(\mathrm{Y})$ berupa Kinerja Karyawan.

$\mathrm{H}_{0}: \mathrm{b}_{1}=\mathrm{b}_{2}=0$, Artinya secara serentak Budaya Organisasi dan Promosi Jabatan berpengaruh positif dan tidak signifikan terhadap Kinerja Karyawan. Sedangkan $\mathrm{H}_{\mathrm{a}}: \mathrm{b}_{1} \neq \mathrm{b}_{2} \neq$ 0, Atinya secara serentak Budaya Organisasi dan Promosi Jabatan berpengaruh positif dan signifikan terhadap Kinerja Karyawan.

Untuk menentukan nilai F, maka diperlukan adanya derajat bebas pembilang dan derajat bebas penyebut, dengan rumus sebagai berikut:

1. $\mathrm{df}($ Pembilang $)=\mathrm{k}-1$

2. $\mathrm{df}($ Penyebut $)=\mathrm{n}-\mathrm{k}$.

Dimana $\mathrm{n}$ adalah jumlah sampel penelitian dan $\mathrm{k}$ adalah Jumlah variabel bebas dan terikat. dalam penelitian ini diketahui jumlah sampel (n) 72 dan jumlah keseluruhan variabel (k) adalah 3 , sehingga diperoleh :

1. $\mathrm{df}$ (pembilang) $=3-1=2$

2. $\mathrm{df}$ (penyebut) $=72-3=69$ 
Nilai $\mathrm{F}$ hitung akan diperoleh dengan menggunakan bantuan SPSS 23 for windows, kemudian akan dibandingkan dengan $\mathrm{F}$ tabel pada tingkat $\alpha=5 \%(2: 69)=3.13$ dengan kriteria uji sebagai berikut:

$\mathrm{H}_{0}$ diterima jika $\mathrm{F}$ hitung $<\mathrm{F}$ Tabel pada

$\alpha=5 \%$

$\mathrm{H}_{0}$ ditolak jika $\mathrm{F}$ hitung $>\mathrm{F}$ tabel pada

$\alpha=5 \%$

Tabel 3. Hasil Uji F Signifikansi Simultan (Uji F) Anova

\begin{tabular}{llllll}
\hline Model & Sum of Squares Df & Mean Square & F & Sig. \\
\hline $\begin{array}{l}\text { 1 Regression } \\
\begin{array}{l}\text { Residual } \\
\text { Total }\end{array}\end{array}$ & 3701.508 & 2 & 1850.754 & 42.125 & $.000^{\mathrm{a}}$ \\
\hline
\end{tabular}

a. Predictors: (Constant), Promosi Jabatan, Budaya Organisasi

b. Dependent Variable: Kinerja Karyawan

Sumber: Hasil Pengelolaan SPSS 23, 2020

Berdasarkan Tabel 3 dapat dilihat hasil Uji F secara simultan, dan diperoleh nilai Fhitung = 42.125 dengan tingkat signifikansi 0,000 . Sedangkan nilai $\mathrm{F}$ tabel $=3,13$ Nilai $\mathrm{F}$ hitung $>\mathrm{Ftabel}$ $(42.125>3,13)$ dan tingkat signifikansi $(0.000<0,05)$ dengan hipotesis $\mathrm{H}_{0}$ ditolak dan $\mathrm{Ha}_{\mathrm{a}}$ diterima sehingga dapat disimpulkan bahwa variabel bebas yaitu Budaya Organisasi (X1) dan Promosi Jabatan (X2) secara bersama-sama berpengaruh positif dan signifikan terhadap variabel Kinerja Karyawan (Y).

\section{SIMPULAN}

Budaya organisasi adalah suatu kekuatan sosial yang tidak tampak yang dapat menggerakkan orang-orang untuk meningkatkan kuantitas kerja, sedangkan promosi jabatan merupakan kondisi yang menggerakan diri sendiri (karyawan) terarah untuk mencapai tujuan atas kualitas kerjanya. Dari pengertian ini bahwa budaya organisasi dan promosi jabatan mempunyai hubungan erat untuk meningkatkan kinerja karyawan. Budaya organisasi adalah suatu budaya yang ciptakan oleh perusahaan untuk mengembangkan kinerja karyawan melalui promosi jabatan, sehingga karyawan lebih giat dalam melaksanakan pekerjaan untuk mendapatkan promosi jabatan yang diberikan perusahaan.

Berdasarkan Uji F bahwa hipotesis yang ditetapkan dalam penelitian ini adalah: "Budaya Organisasi Dan Promosi Jabatan Berpengaruh Positif dan Signifikan Terhadap Kinerja Karyawan Pada PT. Taspen (Persero) Kantor Cabang Utama Medan". Berdasarkan perhitungan koefisien determinan $\mathrm{R}=0,741$ atau $74 \%$ yang artinya hubungan budaya organisasi dan promosi jabatan memiliki hubungan yang erat terhadap kinerja karyawan. Selanjutnya, dari hasil Adjusted R Square 0.537 berarti $53,7 \%$ kinerja karyawan dapat di jelaskan oleh variabel Budaya Organisasi dan variabel Promosi Jabatan. Sedangkan sisanya 46,3\% dapat dijelaskan oleh faktor-faktor lain yang tidak dimasukkan sebagai variabel dalam penelitian ini.

\section{DAFTAR PUSTAKA}

Fikri, M. H., \& Nasution, L. (2018). Pengaruh Kepemimpinan Kepala Sekolah terhadap Efektivitas Sekolah di SMA Negeri 2 Medan. Jurnal Penelitian Pendidikan Sosial Humaniora, 3(2): 389-395.

Gaol, J.L., Ichsan, R.N., Hutabarat, L., (2020), The effect of working atmosphereand discipline towardemployee work productivityinpt. Duta margalestarindomedan, Journal of Advanced Research in Dynamical and Control Systems, 554-564. https://www.jardcs.org/abstract.php?id=4882.

Haryati, E., Suharyanto, A. Hasmayni, B. \& Siregar, F.H. (2019). The Effect of Work Environment and Work Stress on Employee Performance at PT Aneka Gas Industri Tbk Research Article in Proceedings of 
the 2nd International Conference on Social Sciences and Interdisciplinary Studies (formerly ICCSSIS), ICCSIS 2019, 24-25 October 2019, Medan, North Sumatera, Indonesia

Ichsan, R. N. (2019). Kepemimpinan, Komunikasi Dan Efektivitas Kerja Pegawai Pemerintah Kota Lhokseumawe. JUMANT, 11(1): 13-18.

Ichsan, R. N., \& Nasution, L. (2019). Pengaruh Persepsi Kemudahan Penggunaan Dan Persepsi Daya Guna Terhadap Minat Nasabah Menggunakan Mandiri Online Pada PT. Bank Mandiri (Persero) KCP Gatot Subroto 2. In Prosiding Seminar Nasional Hasil Penelitian, 2(2): 1128-1136.

Ichsan, R.N, Surianta, E., \& Nasution, L., (2020). Pengaruh Disiplin Kerja Terhadap Kinerja Pegawai Negeri Sipil (PNS) Dilingkungan Ajudan Jenderal Daerah Militer (AJENDAM) -I Bukit Barisan Medan, Jurnal Darma Agung 28(2): 187-210.

Ichsan, R.N. (2019). Kepemimpinan, Komunikasi Dan Efektivitas Kerja Pegawai Pemerintah Kota Lhokseumawe. JUMANT, 11(1): 13-18.

Latief, A. Rosalina, D. \& Apiska, D. (2019). Analisis Hubungan Antar Manusia terhadap Kinerja Karyawan. Journal of Education, Humaniora and Social Sciences (JEHSS). 1 (3): 127-131.

Latief, A. Zati, M.R. \& Pribadi, K. (2018). Analisis Faktor Faktor Yang Mempengaruhi Kinerja Karyawan. JUPIIS: Jurnal Pendidikan Ilmu-ilmu Sosial, 10 (2): 167-172.

Latief, A., Nurlina, N., Medagri, E., \& Suharyanto, A. (2019). Pengaruh Manajemen Pengetahuan, Keterampilan dan Sikap terhadap Kinerja Karyawan. JUPIIS: Jurnal Pendidikan Ilmu-Ilmu Sosial, 11(2), 173-182. doi:https://doi.org/10.24114/jupiis.v11i2.12608

Mora, Z., Suharyanto, A., Yahya, M., (2020). Effect of Work Safety and Work Healthy Towards Employee's Productivity in PT. Sisirau Aceh Tamiang, Budapest International Research and Critics Institute, 3(2): 753-760.

Nasution, L. and Choiriyah, S. and Rahmat, A. and Alam, H. and Salam. (2020), Utilization of data mining in the processing of average values of high school level national examination at the department of natural sciences in Indonesia. Journal of Advanced Research in Dynamical and Control Systems. 12(6): 2090-2096. https://www.jardcs.org/abstract.php?id=5244

Nasution, L. Improving Quality Of Education Through Standards Educational And Aducational Personnel of SMA Unggulan CT Foundation. EducanduM, 10(2): 12-24.

Nasution, L., \& Ichsan, R. N. (2020). Sosialisasi Pemasaran Dalam Meningkatkan Loyalitas Mahasiswa Dan Alumni Fakultas Hukum Universitas Simalungun. PKM Maju UDA, 1(1): 31-36. Available at: http://jurnal.darmaagung.ac.id/index.php/pkmmajuuda/article/view/702

Nasution, L., \& Putra, M. G. (2018). Pengaruh Bauran Pemasaran dan Kualitas Pelayanan dalam Meningkatkan Loyalitas Mahasiswa Program Studi Manajemen Fakultas Ekonomi UMN Al Washliyah Medan. Jurnal Penelitian Pendidikan Sosial Humaniora, 2(2): 212-219.

Nasution, L., \& Rapono, M. (2018). Strategi Dalam Menghadapi Persaingan Perguruan Tinggi Di Propinsi Sumatera Utara Melalui Analisis SWOT (Studi Kasus UMN Al Washliyah Medan). JKBM (Jurnal Konsep Bisnis Dan Manajemen), 5(1): 9-24.

Nasution, L., Anom, S., \& Karim, A. (2020). Pengaruh Program Sapta Pesona Dan Fasilitas Terhadap tingkat Kunjungan Objek Wisata T-Gardendi Kecamatan Deli Tua Kabupaten Deli Serdang. Jurnal Darma Agung, 28(2): 211-230.

Nasution, L., Fikri, M. H., \& Rapono, M. (2018, April). Penyuluhan Moderenisasi Pembelajaran Berbasis Teknologi Informasi Dan Komunikasi Di SDN 101808 Desa Candirejo Kecamatan Biru-Biru Kab. Deli Serdang. In Prosiding Seminar Nasional Hasil Pengabdian, 1(1): 165-175.

Nasution, L., Ichsan, R.N., Dewi, M.A., Surya, B.P., \& Sumastuti, E, (2020). Emerging Supply and Demand as a Mix of Social, Economic, and Psychological Factors, Journal of critical reviews JCR. 2020; 7 (17): 421424. http://www.jcreview.com/?mno=19953

Nasution, L., Sagala, S., \& Daryanto, E. Kebijakan Kepala Sekolah Sebagai Supervisor Dalam Pengembangan Staf dan Kurikulum Di SMA Negeri 2 Medan. EducanduM, 11(2): 12-23.

Purba, N., Arfanti, Y., Nasution, L., \& Fitriani, R. (2020). Sosialisasi Kewirausahaan Dengan Budaya Malu Untuk Pencegahan Korupsi Di Desa Bandar Sono Kapupaten Batubara. Amaliah: Jurnal Pengabdian Kepada Masyarakat, 4(1): 79-84.

Syardiansah, Latief, A., Daud, M.N., Windi, \& Suharyanto, A, (2020), The Effect of Job Satisfaction and Organizational Culture on Employee Performance of the Royal Hotel in East Aceh District, Budapest International Research and Critics Institute, 3(2): 849-857.

Yusuf, M, and Ichsan, R.N. (2019), Analisis Efektifitas Penggunaan Cadangan Devisa, Utang Luar Negeri dan Ekspor Terhadap Stabilitas Nilai Tukar. Jurnal Penelitian Pendidikan Sosial Humaniora 4(2): 544561. 